\section{Effect of DLC Films with and without Silver Nanoparticles Deposited On Titanium Alloy}

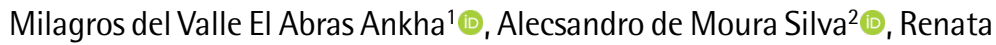
Falchete do Prado $^{2}$, Maiara Penteado Camalionte ${ }^{1}$, Luana Marotta Reis de Vasconcellos ${ }^{1} \mathbb{D}$, Polyana Alves Radi ${ }^{3,4}{ }^{\mathbb{D}}$, Argemiro Soares da Silva Sobrinho ${ }^{4}$, Lucia Vieira ${ }^{3,4}{ }^{-}$, Yasmin Rodarte Carvalho ${ }^{1}$ (D)
'Department of Bioscience and Oral Diagnosis, Institute of Science and Technology, UNESP - Universidade Estadual Paulista, São José dos Campos, SP, Brazil ${ }^{2}$ Department of Prosthodontics and Dental Materials, Institute of Science and Technology, UNESP - Universidade Estadual Paulista, São José dos Campos, SP, Brazil ${ }^{3}$ UNIVAP/IP\&D, Universidade do Vale do Paraíba, São José dos Campos, SP, Brazil ${ }^{4}$ Department of Physic, ITA, Instituto Tecnológico de Aeronáutica, São José dos Campos, SP, Brazil

Correspondence: Renata Falchete do Prado, Avenida Engenheiro Francisco José Longo, 777, 12245000 São José dos Campos, São Paulo, Brasil. Tel: +55-12-3947-9000. e-mail: renata.prado@unesp.br
Key Words: diamond-likecarbon, Osseointegration, plasma-enhanced chemical vapor deposition.

\section{Introduction}

In a healthy natural joint, it is rare for wear to occur because synovial fluid and cartilaginous tissue ensure that there is efficient lubrication between the joint surfaces. However, when a joint loses its structure and therefore its function due to severe diseases, it needs to be replaced by an alloplastic or metal implant (1).

The integration of the biomaterial of the prosthesis has been the subject of intense research in recent years (2)the wear loss was reduced because the contact surface pressure increased with increasing metal insert diameter. However, the increase in wear loss observed for the 48-mm-diameter insert might have been due to the considerable increase in the rotation moment with increasing insert diameter. The tendency of decreasing contact pressure calculated using the Hertzian contact stress equation nearly conformed to the change in wear loss. On the other hand, the wear loss of an artificial hip joint consisting of a cross-linked ultrahigh-molecular-weight polyethylene insert (UHMWPE because this integration must be functionally stable for a long period of time.

One of the weaknesses of alloplastic prostheses is the wear on the articular surfaces, especially on hip and knee joints. Friction and corrosion can generate surface particles and ions, which, after repeated stimulation, may initiate a foreign body response, metallosis and osteolysis $(3,4)$ and thus loss of the prosthesis.

In addition, allergies or hypersensitivity to metals, such as cobalt, chromium, aluminum and vanadium have been reported, in addition to chronic pain, edema and other symptoms of dermatitis $(5,6)$. Titanium may causes hypersensitivity, which may inhibit osteogenesis (5) and consequently inhibit the integration of the biomaterial where it is implanted or positioned (7). In case of implant failures that cannot be explained by infection, impaired healing and overload; the effect of a possible hypersensitivity reaction to titanium may be taken into consideration (7).

The coating of metal surfaces with a protective film may prevent the release of potentially toxic metal ions into the body and promote bone-integration. This would be interesting for use in joint prostheses as well as other biomedical materials, such as plates and screws for osteosynthesis, dental implants and more.

Diamond-like carbon (DLC) film has many features that are desirable for biomedical use, including biocompatibility. It is composed of only carbon and hydrogen, which are biologically compatible with human cells (8). DLC also has high resistance to wear and corrosion, a low coefficient of friction, and high chemical inertia, and depending on the 
deposition process, it can be a strong insulator (9).

The electrical conductivity of DLC film usually present $10^{-10}$ to $10^{-12} \Omega^{-1} \mathrm{~cm}^{-1}$. The addition of metal nanoparticles increases its conductivity. The higher the electrical resistance of a material, the less likely it is to corrode and is thus less likely to lose its initial properties. DLC films are extremely resistant to chemical attack by acids or bases and are stable up to temperatures of $400{ }^{\circ} \mathrm{C}(8)$.

These films can be useful to protect the underlying metal surfaces of the prosthetic joint against wear, corrosion and release of metallic ions. These benefits demonstrate that the study of DLC films is important for its application as a coating for new instruments and implants in biomedical engineering (8). Silver doped DLC films, increased the sp2/ sp3 ratio (improved biocompatibility) with increasing silver concentration, also improve the antibacterial efficiency rose after $24 \mathrm{~h}$ to roughly 100\% for both gram negative and gram positive bacteria (10).

DLC films are commonly used in tribological applications in the biomedical industry and have been proposed for use in increasing the hardness of surfaces in joint replacements. However, the adherence of these films can be a problem, since delamination had been described (11). As an technical resolution to adherence problem, an intermediate layer of silicon has been used between the different types of substrates and the DLC films to increase the adhesion of these coatings (12).

This paper evaluates the in vivo effect of DLC and DLCAg film deposition by plasma-enhanced chemical vapor deposition (PECVD) on titanium alloy samples to pursue its future use as a coating material for prosthetic joints.

\section{Material and Methods}

\section{Experimental Procedures}

In this study, 60 samples of Ti-6Al-4V squares were used that had dimensions of $10.0 \times 10.0 \times 0.5 \mathrm{~mm}$ and rounded edges and two holes for bilateral fixation in the mandible angle of New Zealand rabbits.

All samples were properly sanded in an automatic polishing machine (Erios / Brazil / ICT / UNESP) for standardization and removal of irregularities from surfaces.

Initially, the sample surface was cleaned by immersion in PA acetone for $10 \mathrm{~min}$ in an ultrasound bath to remove oily residues. The samples were divided into three groups: 20 uncoated (G1), 20 coated with a DLC film (G2) and 20 coated with a DLC-Ag film (G3) .

The samples were positioned on the plasma reactor and a physical cleaning was performed using argon plasma. Cleaning was followed by deposition of a silicon interlayer to enhance adhesion and, finally, DLC and DLC, with and without silver nanoparticles (DLC-Ag) films deposition by a PECVD system with a pulsed DC discharge (patent BR 10
2014032374 0). The deposition power was maintained around $200 \mathrm{~W}$. The precursor gas for DLC film was methane (CH4). The precursor for Ag-DLC film was hexane ( $\mathrm{C} 6 \mathrm{H} 14)$, a highly volatile liquid to which silver nanoparticles (30 to $50 \mathrm{~nm}$ ) were added.

\section{Surgical Procedure}

Thirty New Zealand rabbits (R) were used for in vivo studies. The research was analyzed and approved by the local Committee on Ethics in Animal Research, CEUA / ICTCSJC-UNESP, under protocol No. 03/2013. These rabbits were randomly numbered from 1 to 30 and divided into three groups (G1: rabbits numbered 1 to 10; G2: rabbits numbered 11 to 20; G3: rabbits numbered 21 to 30 ). Each rabbit received two samples, from the same group in mandibles, bilaterally. Prior to surgery and euthanasia, the animals were anesthetized with a solution of 13 $\mathrm{mg} / \mathrm{kg}$ of 2-(2,6-xylidine)-5-6-dihydro-4H-1,3-thiazine (Rompun; Bayer do Brasil S/A, São Paulo, SP, Brazil), a muscle relaxant substance with sedative and analgesic properties, and $33 \mathrm{mg} / \mathrm{kg}$ of the general anesthetic ketamine base (Dopalen - Agribands Paulínea, SP Brazil), which were administered intramuscularly. After the surgical installation of the samples, all animals received a single dose of 1,35 $\mathrm{mg} / \mathrm{kg}$ antibiotic (Veterinary pentabiotic - Fort Dodge) intramuscularly. Antisepsis of the skin was carried out with a $0.2 \%$ chlorhexidine gluconate solution.

A linear incision was made parallel to and below the lower edge of the mandible bilaterally, with an approximate length of $1.5 \mathrm{~cm}$, followed by dissection of the planes until reaching the lateral surface of the angle of the mandible. The next step was to expose the medial surface of the mandibular angle to allow the fixation of the samples.

For the adaptation and fixation of the samples, an electric motor (Driller BLM 600 Plus) with a carbide $1 / 2$ drill (KGSorensen) was used at $960 \mathrm{rpm}$ and cooled with sterile saline during drilling. The sample was fixed using a 4-0 braided polyester suture (Ethicon; Johnson \& Johnson, Sãp Paulo, SP, Brazil). The muscle layer was sutured with absorbable 4-0 polyglactin 910 (Ethicon) and the skin with 4.0 silk sutures (Ethicon). Cleansing of the surgical area was done with $0.2 \%$ chlorhexidine. After surgery, the animals were given a normal diet and water "ad libitum" .

The animals were euthanized by an anesthetic overdose and subsequent bleeding after two periods, 15 or 90 days.

Next, bone fragments containing the samples of the right and left mandible were removed, fixed in a $10 \%$ formaldehyde solution for $48 \mathrm{~h}$ and examined by a stereomicroscope for macroscopic characteristics.

\section{Sample Analysis}

The samples were analyzed by a scanning electron 
microscope (SEM) (Zeiss EVO Ma10) with a coupled dispersion spectrometer (EDS) (Oxford Instruments Inca Penta FET X3). The samples were analyzed pre-operatively and after post-operative periods of 15 and 90 days. For analysis of the post-operative period, the samples were separated from the bone and their surfaces were cleaned with dry gauze.

The electrical conductivity of each sample was determined by measuring the resistance with a multimeter prior to fixation in the jaw bones of the rabbits to verify the role of the film as an insulator.

The atomic arrangement of the films was analyzed by Micro Raman scattering spectroscopy (Renishaw 2000 system, with an Ar+-ion laser, $(\lambda=514.5 \mathrm{~nm}))$ with backscattering geometry and was calibrated in relation to the diamond peak. The laser spot diameter was $2.5 \mu \mathrm{m}$, and the power on the sample was $\sim 0.6 \mathrm{~mW}$. All measurements were carried out in air at room temperature. Raman spectroscopy of DLC films and DLC-Ag was performed prior to and after fixing the samples on the animals. The samples were cleaned for the removal of visible bone waste on their surfaces, prior to examination after the in vivo periods. This spectroscopy was also performed on the bone tissue.

Micro-scratch tests were conducted on the sample surfaces using a diamond stylus (Rockwell C 120\%) with a $200 \mu \mathrm{m}$ radius diamond tip to evaluate the adherence between the film and substrate before and after implantation in vivo. The tests were conducted in triplicate, and the critical load ( $\mathrm{LCN}$ ) was evaluated according to the type of damage observed on a scratch track; the LcN was evaluated according to ASTM C1624-05.

\section{Histomorphometric and Histologic Study}

Histological Preparation of Bone Tissue: After fixation with 10\% formaldehyde for $48 \mathrm{~h}$, bone fragments containing the samples were washed with water and treated with increasing concentrations of alcohol $(60 \%$, $70 \%, 80 \%, 90 \%$ and $100 \%)$ for dehydration. Then, they were immersed in xylene (P.A.) for diaphanization. Then, each sample was gradually soaked in a resinous solution using the reagents methyl methacrylate (85\%) associated with dibutyl phthalate (15\%) and $1 \mathrm{~g}$ of benzoyl peroxide.

The resin block containing the anatomical specimen was cut on a Labcut ${ }^{\circledR} 1010$ (EXTEC). The slices were cleaned and polished in a Labpol ${ }^{\circledR}$ 8-12 polishing machine (EXTEC). Then, the cuts were glued with cyanoacrylate ester (Super Bonder ${ }^{\circledR}$ ) on an acetate slide and sanded again in a Labpol ${ }^{\circledR}$ 8-12 (EXTEC). During the sanding process, the slices were observed in an optical microscope to check for minimal thickness with maximal detail.

Histological Analysis: Histological analysis was performed by optical microscopy after staining with toluidine blue, which is indicated for the bone, osteoid tissue and cell nuclei of osteoblasts, osteoclasts and bone marrow cells. It enables the identification of cells in newly formed bone.

Quantitative Analysis of New Bone Formation: A slide for every bone fragment sample was selected at random for histomorphometric analysis of the newly formed bone. Three image fields per slide were taken with a light Zeiss Axiophot 2 microscope (Carl Zeiss, Oberköchen, Germany) coupled with an Axiocam MRC 5 camera (Zeiss) using a $10 \times$ objective and a fixed focus. The digitalized images were submitted to histomorphometric analysis using the AxioVision program, which enables to define and measure the total area of the bone/sample interface and the newly formed bone in this area (Fig. 1).

The data obtained was tabulated and submitted to statistical analysis using the computer program STATISTIC (version 5.5, StatSoft Inc., 2000).

Descriptive (mean and standard deviation) and inferential statistics were obtained. Two-way ANOVA with a parametric repeated measurement was applied. The significance level adopted was the conventional value of $5 \%$.

\section{Results}

\section{Characterization of Samples}

Scanning electron microscopy (SEM) and Energydispersive X-ray spectroscopy (EDS):

The analysis of uncoated samples of Ti-6Al-4V and samples of Ti-6AI-4V coated by DLC and DLC-Ag- by SEM showed that their surfaces exhibited a roughness consistent with the grain of the sandpaper used to

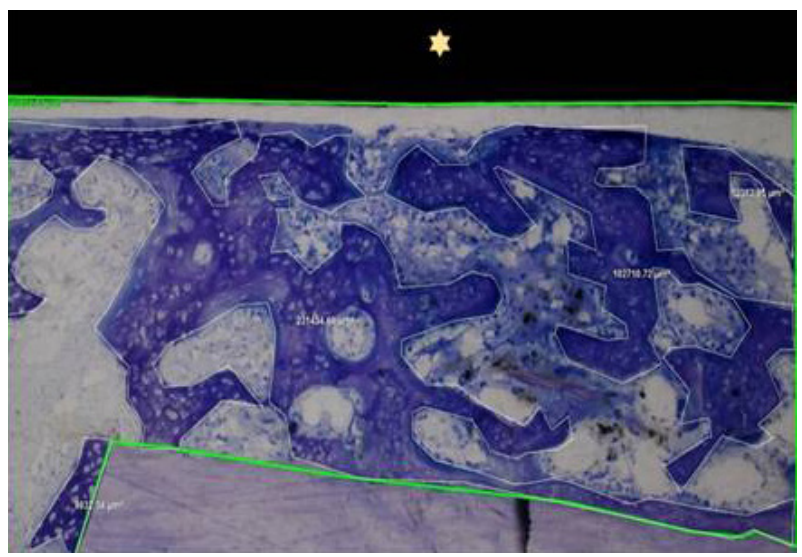

Figure 1. Bone fragment stained with toluidine blue observed by an optical microscope and used for histomorphometric analysis. The green line delineates the total area of the bone/sample interface, the white line outlines areas of new bone formation and the star indicates the sample. Original magnification $10 \times$ 
finishing them. All samples presented changes of their morphology after 15 and 90 days in vivo.

EDS analysis was performed to confirm the chemical composition of the uncoated samples pre-operatively and after post-operative periods of 15 and 90 days. The pre-operative results semi-quantitatively showed the elements present in the alloy: Titanium (Ti), aluminum (AI) and vanadium (V). EDS analysis of the samples coated with DLC and DLC-Ag confirmed the presence of carbon (C) and silicon (Si) in the DLC sample and C, Si and silver $(\mathrm{Ag})$ in the DLC-Ag sample (Table 1).

Post-operative EDS showed the same elements present as in the pre-operative period; however, in both periods, the samples coated by DLC and DLC-Ag showed peaks of calcium (Ca) and phosphorus (P) on their surface, which were not visible macroscopically (Table 1).

\section{Analysis of Raman Spectra of DLC and DLC-Ag Films}

The bone Raman spectrum was recorded as a reference parameter to observe the samples after in vivo hosting.

Figures $2 \mathrm{~A}$ and $2 \mathrm{~B}$ show the typical spectra of a DLC film, including peaks for bands $D$ and $G$, where the band $G$ (1500 to $\left.1600 \mathrm{~cm}^{-1}\right)$ is assigned to stretch links of all pairs of sp2 atoms in both rings and chains, and the $D$ band (1200 to $\left.1400 \mathrm{~cm}^{-1}\right)$ and $D^{\prime}\left(1600-1630 \mathrm{~cm}^{-1}\right)$ are from breathing modes of sp2 atoms in the rings. After 15 days in vivo, the films kept the two DLC typical peaks, but with an increase in the intensity in one or both bands, as can be seen in the R11 sample. This modification demonstrated the incorporation of bone components on the film (Fig. $2 A)$. The adhesion of bone material on the DLC film was also observed in the EDS analyses (Table 1).

After 90 days in vivo, the DLC films showed peaks in the same region as in the initial period. Samples R18, R19 and R20 showed a greater increase at the peak centered at 1300 (Fig. 2B).

Similar results were observed in the Raman Spectra analysis of DLC-Ag films after 15 days and 90 days (Fig. $2 C, D)$. However, the increase in the intensity of the peak centered at 1300 was generally lower than for the pure DLC films.

\section{Micro Scratch Test}

Figure 3 shows representative results obtained from scratching test analysis of the films before and after in vivo hosting for 15 and 90 days. Figures $3 A$ and $D$ show that the DLC film cracks at $-12 \mathrm{~N}$ and the DLC-Ag film resisted until $-20 \mathrm{~N}$ without cracking or delaminating, The presence of silver nanoparticles on the films improved the mechanical resistance. After 15 and 90 days in vivo hosting, the mechanical resistance of the films increased by approximately $-36 \mathrm{~N}$ for DLC films (Fig $3 \mathrm{C}, \mathrm{E})$ and -40 $\mathrm{N}$ for DLC-Ag films (Fig. 3D,F).

\section{Analysis of Electrical Resistance}

The mean resistance of the samples was determined using a multi-meter, and the sample Ti-6AI-4V was classified as a conductor $(100 \mathrm{M} \Omega)$. The results show that coating with DLC films, with or without silver nanoparticles (- $1 \mathrm{M} \Omega$ for both groups) classified samples as semi-conductors. Coating acts as electrical insulation of Ti-6Al-4V alloy substrates where they were applied. The addition of silver nano-particles did not affect the insulating capacity of the DLC film.

\section{Macroscopic Analysis of Bone Tissue Together With The Sample}

Macroscopic analysis was performed with a stereomicroscope at $2.5 \times$ magnification after fixing the fragments in formaldehyde.

After 15 days, the samples were well-positioned, fixed and stable at the location where they were placed. In some samples, a white bone-like tissue partially covering the surface hindered the separation of the samples from the bone. In addition, a material with elastic consistency, similar to cartilage tissue, was also observed in all groups.

After 90 days, the samples presented a hard tissue similar to the bone tissue on the surface, with part of it almost completely covered. In addition, a soft tissue of rubber-like consistency was sometimes observed above the bone and sometimes above the sample. 


\section{5 days}
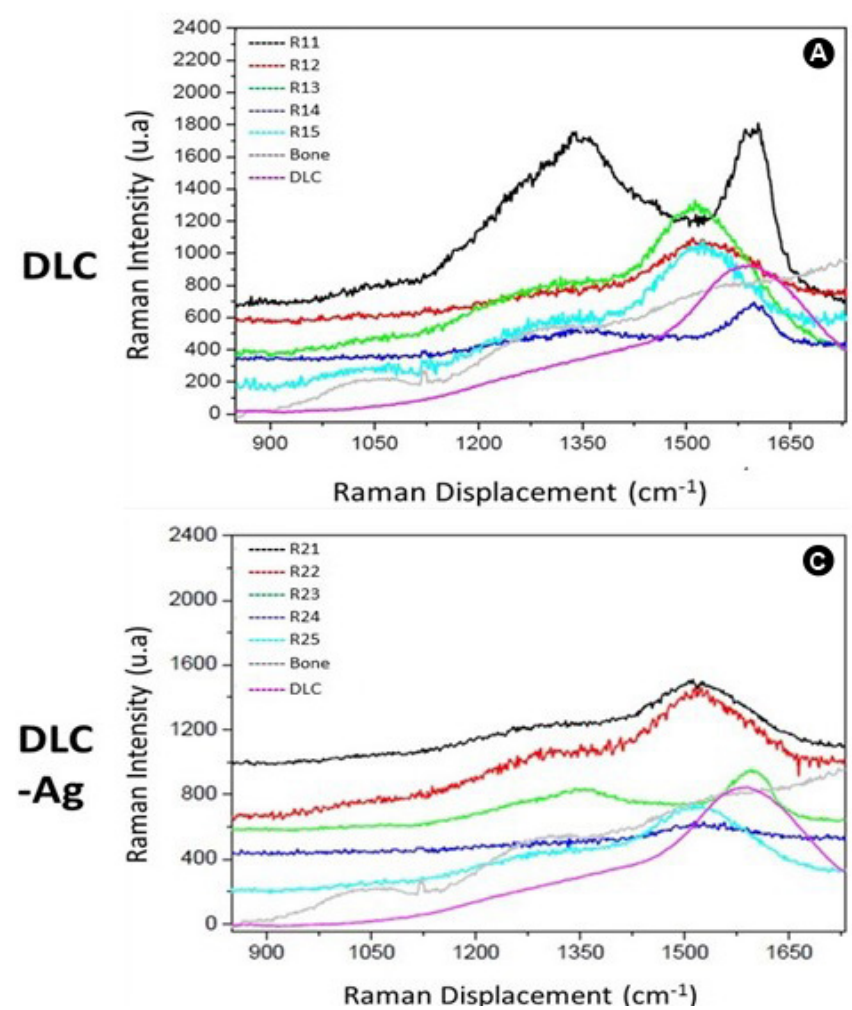

90 days
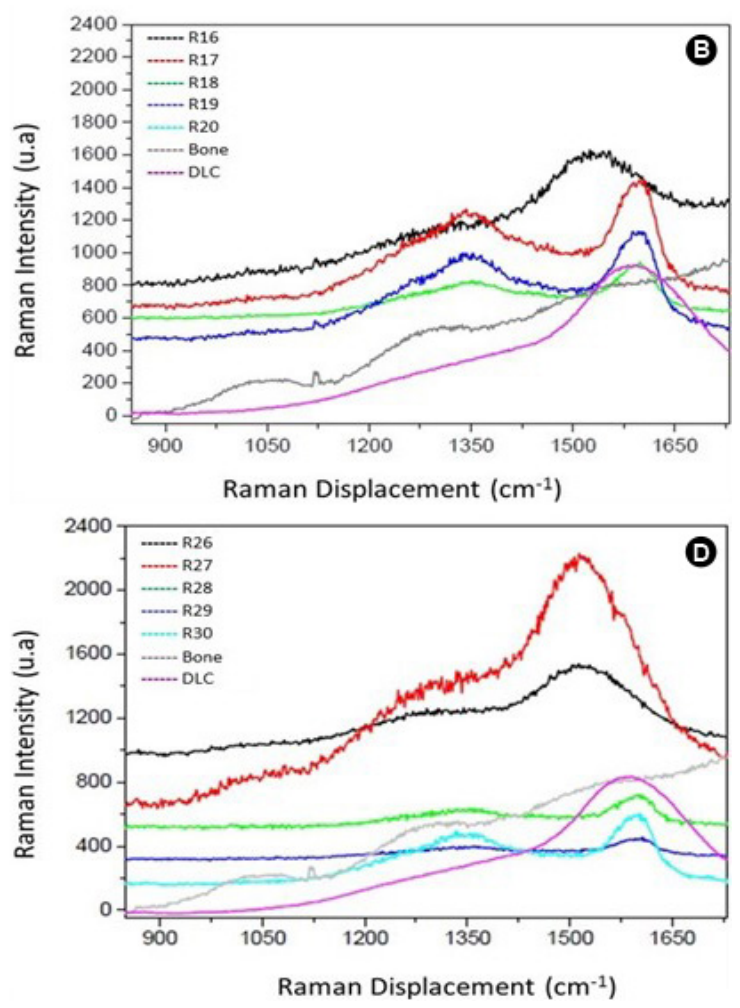

Figure 2. Raman scattering spectroscopy for the DLC and DLC-Ag groups in the 15 day and 90-day periods. The DLC spectra of the initial and bone were used for parameter analysis

\section{DLC}
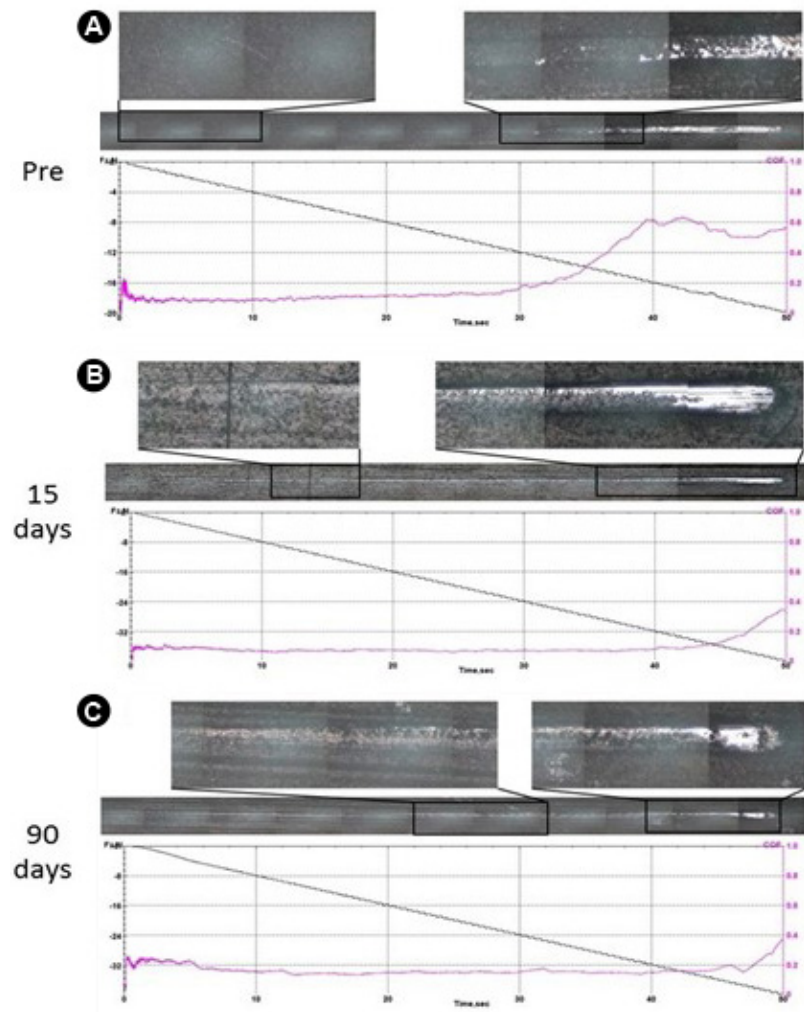

DLC-Ag

D

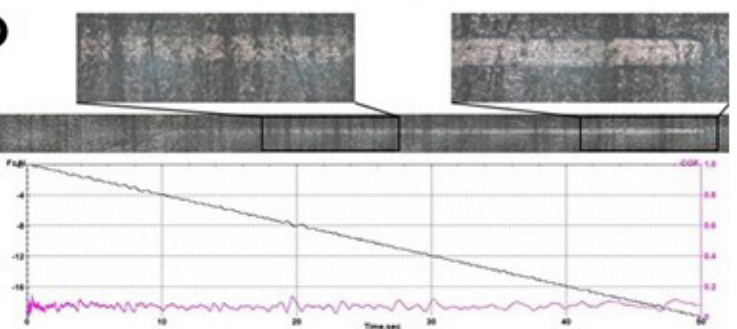

E
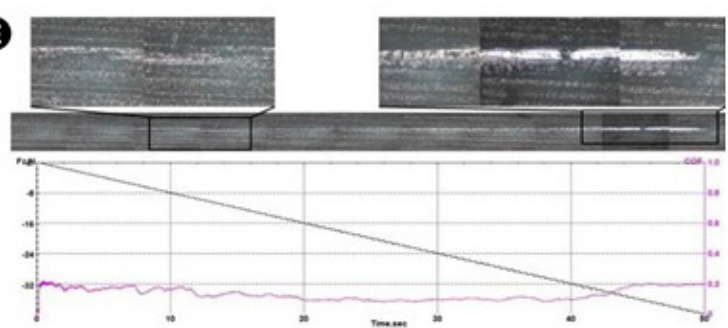

$\boldsymbol{F}$

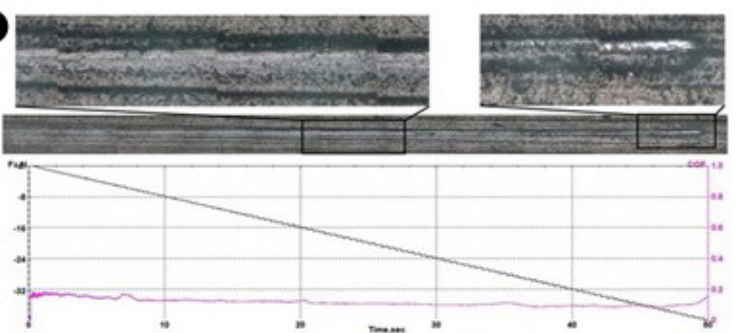

Figure 3. Scratching test graph analyses of DLC and DLC-Ag films before and after in vivo hosting for 15 and 90 days. Above the graphs, the optical images of the track with a zoom on the most important regions can be seen. The graphs show normal loads (black line) and friction coefficients (pink line) 


\section{Histological Analysis of Bone Tissue}

Figure 4 presents the photomicrographs of the histological features observed. New bone formation was observed on the pre-existing bone/sample interface, forming a stable union. Signs of bone remodeling were observed in all groups in both periods.

Microscopically, the specimens presented cross-sections of gnathic bone, with the sample placed above the bone cortex composed of compact bone tissue.
After 15 days, delimitation was observed between the newly formed bone tissue and pre-existing bone cortex. The newly formed bone presented delicate immature trabeculae consisting of partially calcified osteoid tissue, which was formed from pre-existing bone in the direction of the sample. These trabeculae were observed evenly over the sample and exhibited voluminous osteocytes in large lacunae, with osteoblasts arranged linearly around them. Giant cells suggestive of osteoclasts were also observed

\section{5 days}
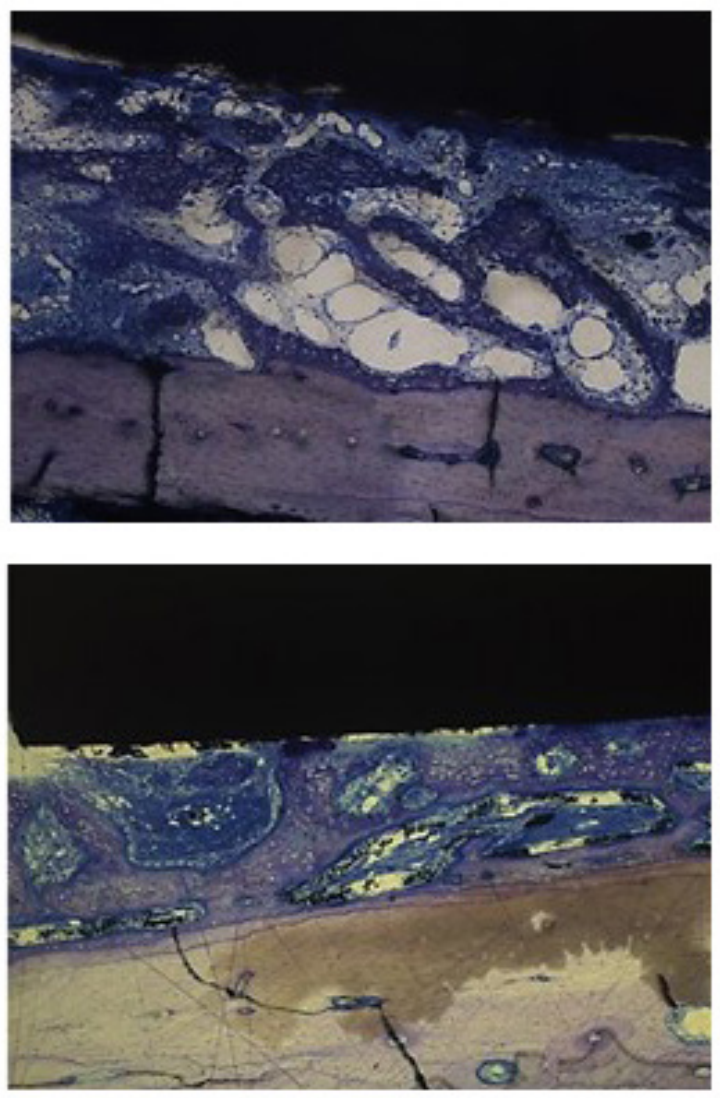

DLC

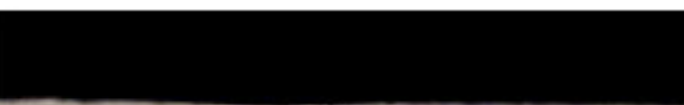

DLC-Ag

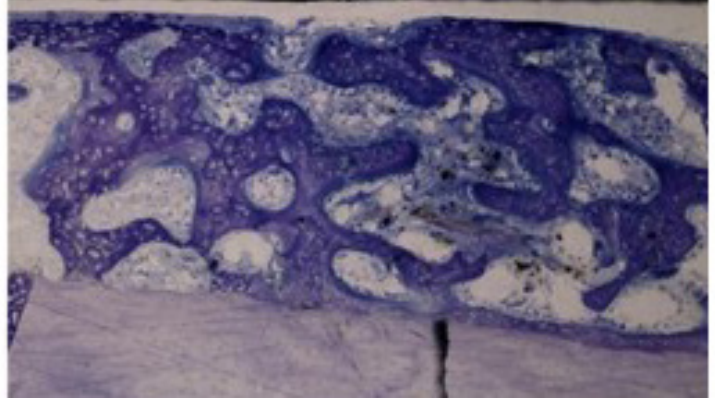

\section{0 days}
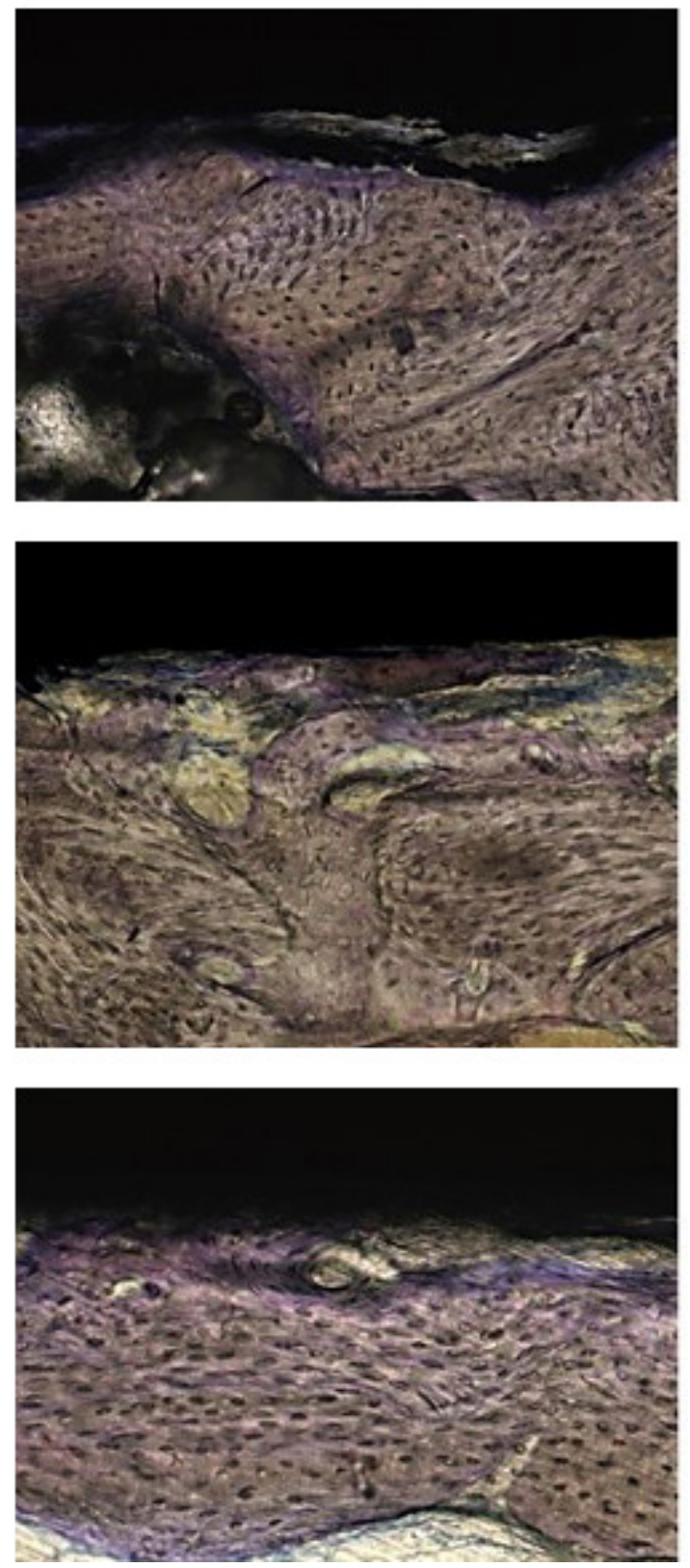

Figure 4. Photomicrographs of the histological features observed for the groups with DLC and DLC-Ag film coating and the group without coating after 15 and 90 days 
around some trabeculae, independent of the group.

After 90 days, the newly formed bone was integrated with the pre-existing bone tissue. It presented a higher degree of maturity and organization than after 15 days and was highly cellularized with several lacunae of osteocytes and Harvey's systems near the sample, regardless of the group evaluated.

\section{Histomorphometric Analysis of New Bone Formation}

The influence of the three conditions of Ti-6Al-4V samples, uncoated and coated with DLC or DLC-Ag, after two different periods of euthanasia (15 and 90 days) in relation to the percentage of new bone formation, is presented in Table 2, constituting six experimental conditions that were studied ( $3 \times 2)$. The normality test of the residual values of the experimental model was designed to check the power of the sample (Anderson Darling test, $p$-value $=0.546>0.05$ ).

To determine the influence of the variables, coating type and period of euthanasia, two-factor ANOVA was applied and showed no significant difference considering the coating type $(p=0.3475)$, but with a statistically significant difference ( $p=0.0001)$ related to the period (0.0001). After 90 days, there was greater new bone formation than in the 15-day period.

To highlight where there was difference in relation to the period, a Tukey multiple comparison test was carried out. The DLC group in the 90-day period showed the highest percentage of new bone formation, which was different from the Ti-6AI-4V, DLC and DLC-Ag groups in the 15-day period. However, the Ti-6Al-4V and DLC-Ag groups in the 90-day period showed no significant difference relative to the other groups. Lower percentages of new bone formation were seen in the DLC-Ag group in the 15-day period and in the Ti-6AI-4V group in the 90-day period (Table 2).

\section{Discussion}

This study evaluated the structural characteristics of

Table 2. Descriptive statistics of the osteogenesis values obtained for five animals (samples) per group, for each period and coating.

\begin{tabular}{cccccccc}
\hline Periods & $\begin{array}{c}\text { Sample } \\
\text { type }\end{array}$ & Mean* $^{*}$ & SD & $\begin{array}{c}\text { CV } \\
(\%)\end{array}$ & Minimum & Maximum & Range \\
\hline \multirow{7}{*}{15 days } & Ti-6Al-4V & $21,66^{\mathrm{B}}$ & 21,26 & 98,14 & 13,37 & 59,60 & 52,44 \\
& DLC & $22,24^{\mathrm{B}}$ & 15,71 & 70,65 & 14,53 & 41,22 & 35,24 \\
& DLC-Ag & $16,17^{\mathrm{B}}$ & 3,08 & 19,04 & 15,09 & 21,60 & 7,40 \\
& Ti-6Al-4V & $48,90^{\mathrm{AB}}$ & 23,40 & 47,86 & 20,40 & 79,00 & 58,60 \\
90 days & DLC & $69,65^{\mathrm{A}}$ & 19,86 & 28,52 & 39,79 & 94,28 & 54,49 \\
& DLC-Ag & $52,80^{\mathrm{AB}}$ & 23,90 & 45,30 & 21,70 & 77,70 & 56,00 \\
\hline
\end{tabular}

SD: standard deviation; CV\%: coefficient of variation. * Values that do not share the same superscript letters are significantly different from each other. $(\mathrm{P}<0.05)$. uncoated and DLC- and DLC-Ag-coated Ti-6AI-4V samples before and after hosting in vivo, as well as the tissue reaction to these materials, in search of a biocompatible and protective film that could be used as a coating for prosthetic joint surfaces.

When titanium is used in sliding surfaces mechanical wear may be observed (13). In several studies, DLC films were used as coating materials for articular prostheses and other biomedical devices and were applied to different substrates by varied deposition systems, and the majority showed good results $(14,15)$, thus wear and corrosion resistance are important. Hard coatings have the potential to reduce the wear and corrosion. Diamond like Carbon (DLC. Because of their physical properties close to the natural diamond DLC films seems to be the ultimate candidate for improving chemical and mechanical wear resistance of articulated implants. However, unfavorable results, such as delamination and foreign body reactions, suggest the need for new studies aiming to demonstrate improved coating films that contain the ideal properties for use in joint prostheses $(11,16)$. Only the first steps have been undertaken in this direction and there is not enough clarity in comprehension of optimal structure of a carbonmetal DLC composite coating and its interaction with bone and tissue cell (17).

Herein, the samples covered with DLC and DLC-Ag films were evaluated before and after in vivo hosting, and no delamination was observed. This demonstrates the high adhesion of the films, which increased with time. This suggests that the incorporation of bone elements ( $\mathrm{Ca}$ and P) on the films, as demonstrated by EDS and Raman spectroscopy, contributed to increasing the mechanical resistance. In addition, the incorporation of silver nanoparticles in the DLC film (DLC-Ag group) also improved its mechanical resistance. A previous study showed that the addition of silver nanoparticles to the DLC film increased the mechanical strength (18). These results suggest that the DLC and DLC-Ag films analyzed in this study can be used as a coating for biomedical devices.

The Raman scattering spectroscopy analysis showed that, after in vivo hosting, the films spectra maintained the typical peaks of DLC and DLC-Ag films for most of the samples, while some showed increasing and/or enlargement of peaks in regions characteristic of bone spectra, probably due to the incorporation of bone elements ( $\mathrm{Ca}$ and $\mathrm{P}$ ) into the film.

A similar result was observed in the DLC films doped with Mo in a NiTi substrate, in which there was formation of a layer of calcium phosphate above the film (19). In 
the uncoated Ti-6Al-4V group, $\mathrm{Ca}$ and $\mathrm{P}$ were not observed. This may be due to changes in their protective layer during in vivo permanency, which could have influenced the release of corrosive products, thus avoiding the interaction of $\mathrm{Ca}$ and $\mathrm{P}$ with the titanium alloy components. In the Ti-6Al$4 \mathrm{~V}$ used for medical implants, $25.1 \%$ of the surface do not have Ti. Consequently, cells would not adhere in these regions (20). Coating with an insulating and biocompatible film would hinder the corrosion of metal alloy and release of ions.

In our study, the osseointegration in the macro and microscopic range was analyzed for the three groups in both in vivo periods. New bone formation covering the samples was also observed. Similar results have been observed with the use of cobalt-chromium substrates coated with DLC, which were implanted in trans-cortical locations in sheep; they also demonstrated osteointegration after 90 days (15). In another study, commercial dental implants coated with DLC were used in Beagles. A higher percentage of bone-implant contact was obtained compared with the control group (commercially pure titanium), yet without a statistically significant difference (21).

Clinically, as a rule the more sp3/sp2 ratio is the better biocompatible property of DLC film. Infection on and around titanium implants still remains a problem which is usually difficult to treat and may lead to eventual implant removal. Surface modification to alter the physicochemical surface properties is a relatively simple and economic way to repel bacteria colonization (22). Growth reduction factor of Staphylococcus aureus ATCC 29213 cultured over Ti covered with Ag-DLC film, was 2.7 times higher compared with that uncoated titanium (17).

Infection is another reason for failure in relation to alloplastic prostheses, which can cause the loss of several temporomandibular prosthetic joints $(23,24)$.

An important property of DLC films is their decreased bacterial adhesion and the silver nanoparticles doped into DLC films provide an additional bactericidal effect that is effective against Staphylococcus aureus (25) and Escherichia coli (26). This property is of paramount importance in materials that will be implemented for biomedical applications, in particular for use in alloplastic implants. The bactericidal effect of silver incorporation in DLC films against Enterococcus faecalis was demonstrated by Cardoso et al. (27) in vitro, with the same type of DLC film used in our study. The authors noted that after three hours, the film with silver presented bactericidal action two times greater than pure DLC film, but after $24 \mathrm{~h}$, the difference between both was not significant. Antimicrobial coverage during the first $24 \mathrm{~h}$ post-operative are essential for avoiding possible infections.

The dose-dependent animal toxicity effects of silver were described by Hadrup and Lam, 2014 (28). In our study, the amount of silver nanoparticles used did not change the osseointegration. However, sp3 bonds content (important to biocompatibility in DLC film) is decreased by silver dopant (29), consequently, it is essential to choose a deposition method that would provide as many sp3 bonds as possible. The DLC-Ag film presented osseointegration similar to that observed in the other groups, demonstrating that the amount of silver nanoparticles that were used did not interfere in this process.

The electrical conductivity observed in DLC films is usually on the order of $10-10$ to $10-12 \Omega-1 \mathrm{~cm}-1$, and therefore, they are considered to be insulators. The addition of metal nanoparticles causes an increase of this conductivity (30). The results of electrical conductivity of both of the films in this study showed that they are not conductors. It is possible that the amount of silver incorporated into the DLC-Ag film was not sufficient to alter the film's conductivity. This would be an additional advantage because the covering of titanium alloy devices with DLC films could prevent the transmission of nerve impulses to the bone and soft tissue in contact with it, avoiding painful sensitivity. Clinical relevance may be achieve because higher levels of conductivity make an environment more corrosive. The corrosion of a DLCcoated metal implant can be 100000 times lower than in an uncoated one. In addition to decreased amount of noxious compounds this means very low probability of delamination of the coating (31).

Despite the promising results obtained herein, this research presents limitations. In case of a bearing, where the main feature is the resistance to wear, rabbits mandible did not provide the most suitable realistic simulation. Metals are a good choice for the supporting material of the hip implant because of their high tensile and fatigue strength (2). In general, the method used herein to deposit DLC film, associated to Ag, may be useful in any biomaterial, since mechanical resistance was superior in this group (DLC-Ag film resisted until $-20 \mathrm{~N}$ without cracking or delaminating). This result presents a clinical relevance, since the main drawback of metals in implants is the chemical and mechanical wear debris, which normally causes tissue reactions (2). In 2008, the use of DLC coatings in hip and in the knee joints originated severe clinical failures and device withdrawal from the market (32) due to delamination of the coating and high polyethylene wear. We believe the PECVD arises as an alternative technique to create improved DLC films, even more if $\mathrm{Ag}$ to be added since $\mathrm{Ag}$ provides antibacterial effect (10).

Concerning characterizations of the DLC and DLC-Ag films, a previous study characterized the two kinds of DLC films obtained herein (33), where substrate presented 
higher Ra values; Ag altered Raman spectra, since group DLC-Ag demonstrated higher type sp2 hybridizations and promoted higher thickness than that obtained in DLC film.

In conclusion, this study demonstrated that samples of Ti-6AI-4V coated with DLC and DLC-Ag films allowed osseointegration and do not suffer structural changes over time in vivo. Therefore, coatings with these films are promising for use in joint prostheses because their behavior is similar to or better than that of Ti-6Al-4V without coating, which is the material that is considered to be the gold standard in joint prostheses and other biomedical applications. Moreover, these films have additional properties that Ti-6Al-4V does not have, including a bactericidal effect, no elements that are toxic to the body and electrical insulation.

\section{Resumo}

0 filme de carbono semelhante a diamante (DLC) é um material de revestimento duro e biocompativel que pode impedir a corrosão com liberação de ions metálicos. Este estudo avaliou as caracteristicas estruturais do filme de DLC, com e sem nanopartículas de prata $(\mathrm{Ag})$, depositadas por plasma (PECVD) em liga de titânio (Ti-6Al-4V) e formação óssea em contato com filmes de DLC. Foram utilizadas 60 amostras de Ti-6Al-4V divididas em: não recobertas, recobertas com DLC e recobertas com DLC-Ag. Após caracterização estrutural, amostras foram fixadas bilateralmente na mandibula de coelhos. Após 15 e 90 dias, as amostras foram novamente caracterizadas e a formação óssea na área foi analisada por histomorfometria. A análise estatística foi realizada por ANOVA dois fatores. Ambos os filmes DLC e DLC-Ag foram firmemente aderidos e mostraram uma alta resistência elétrica sem alterações significativas no espectro Raman após a osseointegração in vivo. Após 15 dias, havia trabéculas ósseas imaturas na interface e cobrindo parcialmente a superfície. Após 90 dias, o osso maduro preencheu a interface e a superfície. Não houve diferença estatisticamente significante entre os três grupos nos dois períodos. Em conclusão, a osseointegração com DLC, DLC-Ag e Ti-6Al-4V não revestido é similar. No entanto, os revestimentos DLC e DLC-Ag têm a vantagem do isolamento elétrico e podem presumivelmente controlar a atividade bacteriana e a corrosão com liberação de ions.

\section{Acknowledgements}

To the "Coordenação de Aperfeiçoamento Pessoal de Nivel Superior" (CAPES) foundation by supporting research and to the Spectroscopy Laboratory/National Institute for Space Research, Brasil by provide its equipment.

\section{References}

1. Wolford LM. Factors to consider in joint prosthesis systems. Proc Bayl Univ Med Cent 2006;19:232-238

2. Okazaki Y. Effect of head size on wear properties of metal-on-metal bearings of hip prostheses, and comparison with wear properties of metal-on-polyethylene bearings using hip simulator. J Mech Behav Biomed Mater 2014;31:152-163.

3. Gustafson $K_{1}$ Jakobsen SS, Lorenzen ND, Thyssen JP, Johansen JD, Bonefeld CM, et al. Metal release and metal allergy after total hip replacement with resurfacing versus conventional hybrid prosthesis. Acta Orthop 2014;85:348-354.

4. Kanatas AN, Needs C, Smith AB, Moran A, Jenkins G, Worrall SF. Short-term outcomes using the Christensen patient-specific temporomandibular joint implant system: a prospective study. Br J Oral Maxillofac Surg 2012;50:149-153.
5. Guo $Y$, Chen D, Cheng M, Lu W, Wang L, Zhang X. The bone tissue compatibility of a new Ti35Nb2Ta3Zr alloy with a low Young's modulus. Int J Mol Med 2013;31:689-697.

6. Kręcisz B, Kieć-Świerczyńska M, Chomiczewska-Skóra D. Allergy to orthopedic metal implants - a prospective study. Int J Occup Med Environ Health 2012;25:463-469.

7. Sicilia A, Cuesta S, Coma G, Arregui I, Guisasola C, Ruiz E, et al. Titanium allergy in dental implant patients: a clinical study on 1500 consecutive patients. Clin Oral Implants Res 2008;19:823-835.

8. Airoldi VJT, Santos LV, Bonetti LF, Capote G, Radi PA, Corat EJ. Tribological and mechanical properties of DLC film obtained on metal surface by an enhanced and low-cost pulsed-DC discharge. Int J Surf Sci Eng 2007;1:417.

9. Fraga MA, Furlan $H$, Pessoa RS, Rasia LA, Mateus CFR. Studies on $\mathrm{SiC}, \mathrm{DLC}$ and $\mathrm{TiO}_{2}$ thin films as piezoresistive sensor materials for high temperature application. Microsyst Technol. Springer-Verlag 2012;18:1027-1033.

10. Písařík $P$, Jelínek $M$, Remsa J, Mikšovský J, Zemek J, Jurek $K$, et al. Antibacterial, mechanical and surface properties of Ag-DLC films prepared by dual PLD for medical applications. Mater Sci Eng C 2017;77: 955-962.

11. Hauert R, Thorwarth K, Thorwarth G. An overview on diamond-like carbon coatings in medical applications. Surf Coatings Technol 2013;233:119-130.

12. Capote G, Bonetti LF, Santos L V., Trava-Airoldi VJ, Corat EJ. Adherent diamond-like carbon coatings on metals via PECVD and IBAD. Brazilian J Phys. 2006;36:986-989.

13. Agins HJ, Alcock NW, Bansal M, Salvati EA, Wilson PD, Pellicci PM, et al. Metallic wear in failed titanium-alloy total hip replacements. A histological and quantitative analysis. J Bone Joint Surg Am 1988;70:347-356.

14. Love CA, Cook RB, Harvey TJ, Dearnley PA, Wood RJK. Diamond like carbon coatings for potential application in biological implants-a review. Tribol Int 2013;63:141-150.

15. Allen $M$, Myer $B$, Rushton $N$. In vitro and in vivo investigations into the biocompatibility of diamond-like carbon (DLC) coatings for orthopedic applications. J Biomed Mater Res 2001;58:319-328.

16. Thorwarth G, Falub CV, Müller U, Weisse B, Voisard C, Tobler M, et al. Tribological behavior of DLC-coated articulating joint implants. Acta Biomater 2010;6:2335-2341.

17. Chekan NM, Beliauski NM, Akulich W, Pozdniak LV, Sergeeva EK, Chernov AN, et al. Biological activity of silver-doped DLC films. Diam Relat Mater 2009;18:1006-1009.

18. Vieira L, Lucas FLC, Fisssmer SF, dos Santos LCD, Massi M, Leite PMSCM, et al. Scratch testing for micro- and nanoscale evaluation of tribocharging in DLC films containing silver nanoparticles using AFM and KPFM techniques. Surf Coatings Technol 2014;260:205-213.

19. Anandan C, Mohan L, Babu PD. Electrochemical studies and growth of apatite on molybdenum doped DLC coatings on titanium alloy $\beta-21 S$. Appl Surf Sci. North-Holland 2014;296:86-94.

20. Yang $\mathrm{W}-\mathrm{E}$, Huang $\mathrm{H}-\mathrm{H}$. Improving the biocompatibility of titanium surface through formation of a $\mathrm{TiO}_{2}$ nano-mesh layer. Thin Solid Films 2010;518:7545-7550.

21. De Maeztu MA, Braceras I, Alava JI, Sánchez-Garcés MA, Gay-Escoda C. Histomorphometric study of ion implantation and diamond-like carbon as dental implant surface treatments in beagle dogs. Int J Oral Maxillofac Implants 22:273-279.

22. Zhao L, Chu PK, Zhang Y, Wu Z. Antibacterial coatings on titanium implants. J Biomed Mater Res Part B Appl Biomater 2009;91B: 470-480.

23. Wolford LM, Rodrigues DB, McPhillips A. Management of the Infected Temporomandibular Joint Total Joint Prosthesis. J Oral Maxillofac Surg 2010;68:2810-2823

24. Mercuri LG. Total joint reconstruction-autologous or alloplastic. Oral Maxillofac Surg Clin North Am 2006:18:399-410.

25. Narayan RJ, Abernathy $H$, Riester L, Berry CJ, Brigmon R. Antimicrobial Properties of Diamond-like Carbon-Silver-Platinum Nanocomposite Thin Films. J Mater Eng Perform. Springer-Verlag 2005;14:435-440.

26. Cloutier $M$, Tolouei $R$, Lesage 0 , Lévesque $L$, Turgeon $S$, Tatoulian $M$, et al. On the long term antibacterial features of silver-doped diamondlike 
carbon coatings deposited via a hybrid plasma process. Biointerphases 2014;9:029013.

27. Cardoso $M$, Sangalli J, Koga-Ito $C Y$, Ferreira LL, da Silva Sobrinho AS, Nogueira L. Abutment coating with diamond-like carbon films to reduce implant-abutment bacterial leakage. J Periodontol 2016;87:168-174.

28. Hadrup N, Lam HR. Oral toxicity of silver ions, silver nanoparticles and colloidal silver - A review. Regul Toxicol Pharmacol 2014;68:1-7.

29. Linder S, Pinkowski W, Aepfelbacher M. Adhesion, cytoskeletal architecture and activation status of primary human macrophages on a diamond-like carbon coated surface. Biomaterials 2002;23:767-773.

30. Grill A. Electrical and optical properties of diamond-like carbon. Thin Solid Films 1999;355:189 \pm 193

31. Tiainen V-M. Amorphous carbon as a bio-mechanical coating mechanical properties and biological applications. Diam Relat Mater

\section{$2001 ; 10: 153-160$}

32. Piconi C, De Santis V, Maccauro G. Clinical outcomes of ceramicized ball heads in total hip replacement bearings: a literature review. J Appl Biomater Funct Mater 2017;15:e1-e9.

33. de Moura Silva $A$, de Figueiredo $V M G$, do Prado $R F$, de Fátima Santanta-Melo G, del Valle El Abras Ankha M, de Vasconcellos LMR, et al. Diamond-like carbon films over reconstructive TMJ prosthetic materials: Effects in the cytotoxicity, chemical and mechanical properties. J Oral Biol Craniofacial Res 2019;9:201-207.

Received March 25, 2019

Accepted June 24, 2019 